\title{
DIFFERENCE BETWEEN DOMESTIC AND INTERNATIONAL VISITORS TO GASTRONOMIC EVENTS: CASE STUDY OF ISTRIA, CROATIA
}

\author{
Klara Trošt Lesić
}

https://doi.org/10.20867/tosee.05.7

\begin{abstract}
Purpose - The purpose of this paper is to analyse the role of events in the tourism offer of Istria, with a particular accent on an analysis of the selected gastronomic events. By this paper, the intention is to determine whether there is a difference between domestic and foreign visitors to gastronomic events in all listed goals; therefore, the main research question reads: Is there a difference in the satisfaction and experiences of event visitors depending on whether they are domestic or foreign?

Methodology - The research was conducted during the period of eight months in 2016, between April and November. Primary data was collected through a self-completed questionnaire, by surveying visitors in 22 different gastronomic events, in 22 different tourism destinations in Istria. During the course of the research, 1,227 respondents were surveyed, both domestic and foreign event visitors. The research methodology was based on a fundamental approach which includes the use of descriptive analyses.

Findings - By analysing the experiences of gastronomic event visitors, it is determined that $80.1 \%$ of the respondents realised a memorable experience. Domestic visitors are the most satisfied with the diversity of the gastronomic offer, while they are the least satisfied with the prices. It is completely opposite with foreign guests; they are satisfied with the prices, but less satisfied with what is on offer.

Contribution - Based on the research, five most frequent challenges are identified which event organisers come across and which relate to gastronomic, but also to other kinds of events.

Keywords gastronomic events, domestic visitors, foreign visitors, event experience, event satisfaction

\section{INTRODUCTION}

With the increase in understanding and importance of experience in tourism destination offer, event organisers face the challenge of organisation of events which will provide visitors with experiences which are as intense as possible. The experience design theory is based on two steps. Firstly, it is necessary to identify the event or destination unique selling proposition and then to identify the ideal event visitor. Based on the obtained data, the event organiser is able to design a programme which will provide event visitors with experiences to remember. Although, back in 1997, Getz (1997, p. 251; Yeoman et al 2007, p. 19) determined that "many events suffer from "product orientation" that is, they try to sell their event with little or no regard for what potential customers need, want and will pay for". Taking into consideration of event visitors' needs has only recently become reality in the amateur practice of event organisation in Croatia. A year after Getz
\end{abstract}


ToSEE - Tourism in Southern and Eastern Europe, Vol. 5, pp. 705-714, 2019

K. Trošt Lesić: DIFFERENCE BETWEEN DOMESTIC AND INTERNATIONAL VISITORS TO ...

(1997), Pine \& Gilmore (1998) wrote about the experience economy and elements which an event programme must contain and which will intrigue, delight, educate, relax and emotionally bond visitors and participants. By structuring such experiences, not only satisfied and loyal visitors are created, but also a basis for sustainable event development.

The purpose of this paper is to analyse the role of events in the tourism offer of Istria (Croatia), with a particular accent on an analysis of the selected gastronomic events. The research goals are to analyse: 1) the calendar of gastronomic events in Istria by months and staging clusters, 2) the profile of visitors to selected gastronomic events, 3) the experiences of visitors to gastronomic events, 4) visitors' expenditure at events, 5) satisfaction with the hospitality aspects of gastronomic events, 6) satisfaction with the organisational aspects of gastronomic events and 7) opinions about the valuable aspects of gastronomic events. By this paper, the intention is to determine whether there is a difference between domestic and foreign visitors to gastronomic events in all listed goals; therefore, the main research question reads: Is there a difference in the satisfaction and experiences of event visitors depending on whether they are domestic or foreign?

By a detailed analysis of gastronomic events and by understanding visitors' behaviour, quality personalised information can be obtained which event managers can use in order to improve the event quality by directing their actions towards minimization or removal of the identified problem areas.

\section{THEORETICAL FRAMEWORK}

Culinary tourism is a niche area of tourism studies that has grown rapidly in recent years in terms of tourism research and tourism product development. The culinary tourism niche market presents a new venture for destination marketing, which can improve the attractiveness of a destination without necessarily involving major new product development. According to Hall (2006, p. 303): "Culinary tourism is typically regarded as especially important in rural areas because the relationship between food and tourism represents a significant opportunity for product and marketing development as well as for rural diversification and is often encouraged through the intervention of national and regional public agencies."

A concept similar to culinary tourism is food tourism. Food tourism can be defined as visits to restaurants, wine or olive oil tasting venues, food festivals and primary and secondary food producers (Hall and Mitchell, 2006). Food tourism can also be viewed as a subsidiary of cultural tourism, with local cuisine as a product of the local culture and of the natural environment. Hall and Mitchell (2006, p.137) offer two perspectives; one from the perspective of the consumer, and one from a tourism perspective: "From the perspective of the consumer, food is an integral component of daily life and therefore of travel. From a tourism perspective, food offers potential for firm and destination marketing opportunities, specialized tourism products based on food experiences, and the possibility of enhancing economic linkages between tourism and agricultural production." 
ToSEE - Tourism in Southern and Eastern Europe, Vol. 5, pp. 705-714, 2019

K. Trošt Lesić: DIFFERENCE BETWEEN DOMESTIC AND INTERNATIONAL VISITORS TO ...

The interdependence between gastronomy and tourism is reflected through attracting tourists into the destination where the food which tourists consume represents local culture, thus becoming an important part of the tourist destination image. According to the Global Report on Food Tourism (UNWTO, 2012) data, over a third of tourist expenditure is devoted to food; therefore, the cuisine of the destination is an aspect of utmost importance in the quality of the holiday experience. Furthermore, according to the Second Global Report on Gastronomy Tourism (UNWTO, 2017, p. 12) "Gastronomy has demonstrated to be a major source of identity and pride for local communities and it is also able to attract tourist flows to less visited regions, consequently generating spending in a way that is more equitable throughout the entire region." Gastronomy tourism, which is realised by participation in gastronomic events, enables tourists looking for authenticity to realise a memorable gastronomic experience.

Apart from numerous tourist, economic, social and cultural event functions, food festivals, such as the exhibition of agricultural food products, enable the participants, who are also at the same time the producers, to build their image and promote and sell their own products, to establish relationships with other producers who participate in the exhibition, as well as to take part in the competition part of the event.

With the increase in understanding and importance of experience in tourism destination offer, event organisers face the challenge of organisation of events which will provide visitors with experiences which are as intense as possible. Pine and Gilmore (1998) describe the advantages of participation in events as experiences to remember. They believe that, in order to design programmes which will provide such experiences, tourists and visitors need to be intrigued, delighted, educated, relaxed and emotionally attached. By structuring of such experiences not only satisfied and loyal visitors are created, but also a basis for sustainable event development.

Pine and Gilmore (1998) stress that, in the times of experience economy, companies and event organisers must deliberately and purposefully design events which engage and require compensation, as opposed to current experiences, when many companies simply wrapped experiences in their traditional offer in order to achieve better sales. In their research, Oh, Fiore \& Jeoung (2007) conclude that the "new demand for unique and unforgettable experiences requires companies to develop special added values for the products and services which have already reached a consistently high quality level". As in food tourism, through quality designed programmes, visitors can immerse themselves in the culture and heritage of the area and go through experiences to remember in a unique and personalised way Copolla (2016).

\section{METHOD}

The research was conducted during the period of eight months in 2016, between April and November, throughout the pre-season, the high tourist season and the post-season. Primary data was collected though a self-completed questionnaire, by surveying visitors to 22 different gastronomic events, in 22 different tourism destinations in the County of Istarska in Croatia. Out of the total number of destinations included in the research, seven are located on the coast, while the remaining 15 were in the inland areas of Istria. The 
ToSEE - Tourism in Southern and Eastern Europe, Vol. 5, pp. 705-714, 2019

K. Trošt Lesić: DIFFERENCE BETWEEN DOMESTIC AND INTERNATIONAL VISITORS TO ...

research sample consisted of gastronomic events which satisfied the following conditions: 1) long-time staging tradition, 2) gastronomic offer of autochthonous, in some areas, even forgotten dishes and Istrian cuisine specialities and 3) traditional methods of preparation of Istrian dishes (bell, wood burning stove, bread oven).

During the course of the research, 1,227 respondents were surveyed, both domestic and foreign event visitors. The sample of this research can be characterised as a convenience sample, and its size is considered to be sufficient for making conclusions, given that the number of respondents in similar research amounted to 415 (Taks et al. 2009), 523 (Woo et al. 2011), 726 (Lee, Lee and Wicks 2004).

An original research instrument was developed; a structured questionnaire consisting of closed-type questions. The research instrument intended for event visitors consisted of 19 questions and four parts: socio-demographic questions, information about the event, motivation for attendance and company, expenditure at the event, satisfaction with the event and experiences and questions about the tourism destination. The questionnaire was tested before application. The testing of the questionnaires resulted only in insignificant reformulations of the questions.

The field research was carried out by engagement of interviewers-volunteers, with whom, prior to conduct of the survey, an informative meeting was held, as well as a short education. At the meeting, the survey method was explained and how to approach guests, all the questions from the survey were explained, as well as what to do in the event that guests are not interested in completing the survey or in the event of inappropriate reactions by visitors. The interviewers had to have a good command of at least one foreign language in order to communicate with foreign event visitors. For the needs of the research, a total of 43 interviewers-volunteers were engaged.

The collected primary data was processed by using the software package SPSS 22.0. The research methodology was based on a fundamental approach which includes the use of descriptive analyses (basic sample characteristics, which means value, percentage, median, mean, mean rank).

\section{RESULTS}

\subsection{Calendar of gastronomic events in Istria}

Based on the analysis of the calendar of events held in Istria during the course of the year 2016, it is determined that a total of 1,760 events were staged, of which there were three a day during the pre- and post-season periods, while, during the high season period, i.e. the months of July and August, there were as many as 14 a day. Out of the total number of events, $10 \%$ represent gastronomic events. By comparison of the number of gastronomic events held in the years 2009 and 2016, it is determined that the number of gastronomic events almost doubled; it increased from 97 to 173. The analysis according to the months of staging shows that gastronomic events are the most numerous during the summer months (July and August). However, their seasonality is not so pronounced as a large number of gastronomic events are held in pre- and post-season periods. 
ToSEE - Tourism in Southern and Eastern Europe, Vol. 5, pp. 705-714, 2019

\section{Graph 1: Comparison of gastronomic event offer in 2009 and 2016}

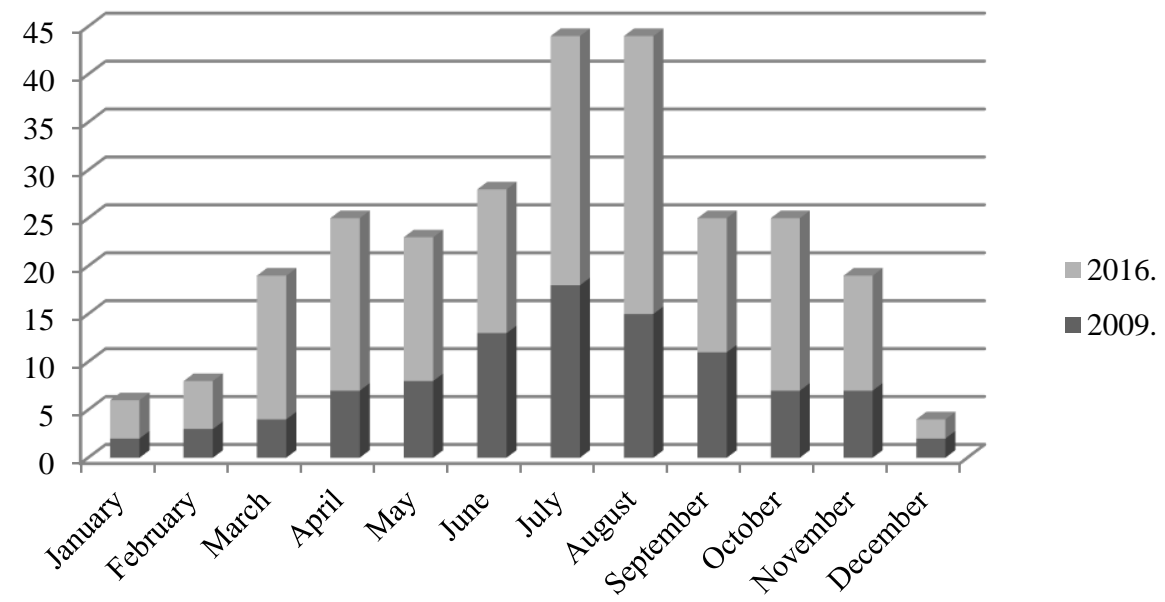

Source: Data processed by authors

The comparison between the years 2009 and 2016 shows that the number of gastronomic events in Istria has considerably increased in recent years, and that it doubled or tripled in all the months except for the month of December (graph. 1). The largest increase in the number of events is recorded in August, namely by 14 events more in 2016 in comparison to 2009. In the months of March, April and November, an increase in the number of events is also recorded, namely by 11 events more in 2016 in comparison with 2009.

Graph 2: Comparison of gastronomic event offer according to clusters in 2009 and 2016
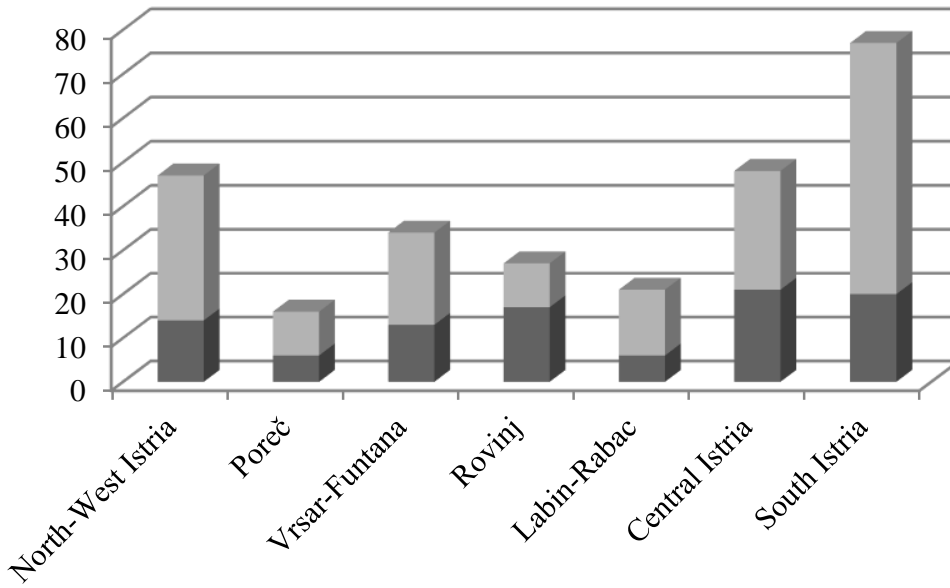

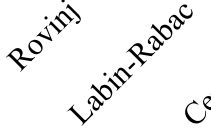

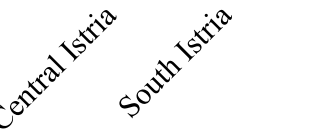


ToSEE - Tourism in Southern and Eastern Europe, Vol. 5, pp. 705-714, 2019

K. Trošt Lesić: DIFFERENCE BETWEEN DOMESTIC AND INTERNATIONAL VISITORS TO

The analysis of the gastronomic event offer, according to clusters in 2016 shows that the largest number of events takes place in the cluster of South Istria, 57 (Pula and Medulin), followed by the cluster of North-West Istria, 33 (Novigrad, Umag, Brtonigla and Buje) and Central Istria, 27 (graph. 2). The lowest number of gastronomic events is held in Rovinj and Poreč, which corresponds to the strategy of tourism destination development, which, like Rovinj, focused on exclusive sports events or congress tourism.

The comparison between the years 2009 and 2016 shows that the number of gastronomic events in all the clusters has increased, except for the cluster of Rovinj. The largest increase in the number of events is recorded in the cluster of South Istria, namely by 37 events more in 2016 in comparison with the year 2009 and in the cluster of North-West Istria, namely by 19 events more in 2016 in comparison with the year 2009. In 2009, the cluster of Central Istria had the largest number of gastronomic events in Istria, whereas, in 2016, it occupied third place. In comparison with other clusters, the number of gastronomic events in the cluster of Rovinj during the last seven years decreased from 17 gastronomic events per year to 10 (graph. 2).

\subsection{Profile of visitors}

The sample of the study consisted of 1,227 respondents of which 708 were domestic event visitors (57.7\%) and 519 international event visitors (42.3\%). 58.4\% of the respondents where female and $41.6 \%$ where male. Most of the respondents have secondary school qualification (44.4\%) and are between 35 and 44 years old $(27.41 \%)$. According to their profession, the largest number of visitors are employed $(44.8 \%)$, followed by self-employed (16.9\%) and pensioners (15.6\%). According to the country of origin, most visitors come from Croatia $(57.7 \%)$, followed by Slovenia (13.2\%), Italy $(9 \%)$, Germany $(8.3 \%)$ and Austria $(2 \%)$.

Table 1: Socio-demographic characteristics of gastronomic event visitors in Istria

\begin{tabular}{|c|c|c|c|}
\hline \multicolumn{2}{|c|}{ AGE (Mean 42.89, St.D. 14.49) } & \multicolumn{2}{c|}{ COUNTRY OF ORIGIN } \\
\hline $16-24$ & $9.43 \%$ & Croatia & $57.7 \%$ \\
\hline $25-34$ & $21.60 \%$ & Slovenia & $13.2 \%$ \\
\hline $35-44$ & $27.41 \%$ & Italy & $9 \%$ \\
\hline $45-54$ & $16.56 \%$ & Germany & $8.3 \%$ \\
\hline $55+$ & $25 \%$ & Austria & $2 \%$ \\
\hline EDUCATION & $4.7 \%$ & PROFESSION & $44.8 \%$ \\
\hline Primary school & $44.4 \%$ & Self-employed & $16.9 \%$ \\
\hline Secondary school & $41.2 \%$ & Pensioners & $15.6 \%$ \\
\hline University & $9.7 \%$ & Managers & $9.7 \%$ \\
\hline
\end{tabular}

Source: Data processed by authors

The analysis of experience based on a sample of visitors to the Istrian gastronomic events $(\mathrm{N}=1,227$ visitors) shows that the experience to remember dominates with $80.10 \%$ (memorable experience), i.e. positive experience, which event visitors will remember for a long time. Transforming experiences or experiences which result in permanent changes in attitude and behaviour make up for $16.4 \%$ of experiences of visitors to the Istrian gastronomic events. The lowest percentage of $3.5 \%$ relates to the basic experiences 
ToSEE - Tourism in Southern and Eastern Europe, Vol. 5, pp. 705-714, 2019

K. Trošt Lesić: DIFFERENCE BETWEEN DOMESTIC AND INTERNATIONAL VISITORS TO ...

which are defined as sensory reactions to stimulation, but without any substantial effects which would make them remain on one's mind for a long time.

Table 2: Analysis of experiences of domestic and international event visitors

\begin{tabular}{|c|c|c|c|c|}
\hline \multirow{2}{*}{ EXPERIENCES } & \multicolumn{4}{|c|}{ VISITORS } \\
\cline { 2 - 5 } & DOMESTIC & $\%$ & INTERNATIONAL & $\%$ \\
\hline Basic & 28 & 4.1 & 17 & 3.6 \\
\hline Memorable & 528 & 76.7 & 398 & 84.3 \\
\hline Transforming & 132 & 19.2 & 57 & 12.1 \\
\hline & $\mathbf{6 8 8}$ & $\mathbf{1 0 0}$ & $\mathbf{4 7 2}$ & $\mathbf{1 0 0}$ \\
\hline
\end{tabular}

$\mathrm{N}=1,168$

Source: Data processed by authors

By an additional analysis of experiences according to the visitors' country of origin it is determined that, by taking part in gastronomic events in Istria, the domestic visitors experienced a larger share of transforming experiences, namely, $19.2 \%$, while $12.1 \%$ of international visitors experienced transforming experiences.

Table 3: Average expenditure in $€$ at gastronomic events in Istria

\begin{tabular}{|r|c|c|}
\hline \multirow{2}{*}{} & \multicolumn{2}{|c|}{ AVERAGE EXPENDITURE } \\
\cline { 2 - 3 } & DOMESTIC VISITORS & INTERNATIONAL VISITORS \\
\hline Food & $€ 4.60$ & $€ 6.00$ \\
\hline Drink & $€ 3.80$ & $€ 4.20$ \\
\hline Shopping & $€ 4.20$ & $€ 5.40$ \\
\hline TOTAL & $€ 12.60$ & $€ 15.60$ \\
\hline
\end{tabular}

Source: Data processed by authors

Average expenditure of domestic visitors to events equals $€ 12.60$ per person, of which the largest part is spent on food, followed by purchases at events and drinks. On the other hand, international event visitors spend more than the domestic visitors and their average expenditure at gastronomic events is $€ 15.60$. Both international and domestic visitors spend the most on food, followed by purchases, most often of autochthonous souvenirs offered by the local manufacturers and on drink. By the detailed analysis of expenditure, it is determined that domestic gastronomic event visitors on average spend $€ 3.00$ less than international visitors. The surveyed visitors are most satisfied by the courtesy of the staff working at events (4.55) and suitability of event venues (4.46). The visitors to Istrian gastronomic events are least satisfied by the availability of toilet facilities (3.62), availability of parking spaces (3.94) and availability of information about event staging (3.95). 
ToSEE - Tourism in Southern and Eastern Europe, Vol. 5, pp. 705-714, 2019

K. Trošt Lesić: DIFFERENCE BETWEEN DOMESTIC AND INTERNATIONAL VISITORS TO ...

Table 4: Comparison of domestic and international event visitors' satisfaction with organisational aspects of events

\begin{tabular}{|l|l|c|c|c|}
\hline SATISFACTION ELEMENTS & \multicolumn{1}{|c|}{ VISITORS } & N & Mean & St.D. \\
\hline \multirow{2}{*}{$\begin{array}{l}\text { Availability of information about } \\
\text { event staging }\end{array}$} & INTERNATIONAL & 422 & 3.86 & .856 \\
\cline { 2 - 5 } & DOMESTIC & 696 & 4.00 & .889 \\
\hline \multirow{2}{*}{ Availability of toilet facilities } & INTERNATIONAL & 414 & 3.45 & 1.056 \\
\cline { 2 - 5 } & DOMESTIC & 678 & 3.68 & 1.160 \\
\hline \multirow{2}{*}{ Staff professionalism } & INTERNATIONAL & 430 & 4.33 & .750 \\
\cline { 2 - 5 } & DOMESTIC & 698 & 4.50 & .715 \\
\hline
\end{tabular}

Source: Data processed by authors

The comparison of satisfaction with event organisational aspects between domestic and international visitors shows that there is a difference in satisfaction with three aspects, namely: availability of information about event staging, availability of toilet facilities and staff professionalism at events (table 4). Domestic visitors and visitors from abroad are most satisfied with staff professionalism at events, while visitors from abroad are less satisfied with availability of information about event staging and availability of toilet facilities in relation to domestic visitors.

The surveyed visitors are most satisfied with the good taste of the dishes offered (4.40) at Istrian gastronomic events, while they are least satisfied with the size of the portions of offered dishes (4.01).

The comparison of satisfaction with hospitality aspects of events between the domestic and international visitors shows that there is a difference in satisfaction with three aspects, namely, with the price of the offered dishes, the portion size and the variety of offer (table 5). The domestic visitors and the visitors from abroad have completely opposite opinions regarding satisfaction with event hospitality aspects. The visitors from abroad believe that the prices are reasonably determined and that the portions are sufficiently large, while domestic visitors believe that the offer choice is more varied.

Table 5: Comparison of satisfaction of domestic and international visitors with event hospitality aspects

\begin{tabular}{|l|l|c|c|c|}
\hline SATISFACTION ELEMENTS & \multicolumn{1}{|c|}{ VISITORS } & N & Mean & St.D. \\
\hline \multirow{2}{*}{$\begin{array}{l}\text { Prices of offered dishes are } \\
\text { reasonable }\end{array}$} & INTERNATIONAL & 345 & 4.18 & .880 \\
\cline { 2 - 5 } $\begin{array}{l}\text { Portions of offered dishes are } \\
\text { sufficiently large }\end{array}$ & DOMESTIC & 617 & 4.04 & .993 \\
\hline \multirow{2}{*}{ Gastro offer is varied } & DOMESTIC & 308 & 4.09 & .954 \\
\cline { 2 - 5 } & INTERNATIONAL & 541 & 3.93 & 1.070 \\
\cline { 2 - 5 } & DOMESTIC & 602 & 4.03 & .871 \\
\hline
\end{tabular}

Source: Data processed by authors

The surveyed visitors agree most with the statement that they will talk positively about Istrian gastronomic events (4.48), while they agree least with the statement that gastronomic events offered greater value in comparison with similar gastronomic events they visited (3.83). 
ToSEE - Tourism in Southern and Eastern Europe, Vol. 5, pp. 705-714, 2019

K. Trošt Lesić: DIFFERENCE BETWEEN DOMESTIC AND INTERNATIONAL VISITORS TO ...

Table 6: Comparison of agreement with statements by domestic and international visitors concerning value aspects of events

\begin{tabular}{|l|l|c|c|c|}
\hline \multicolumn{1}{|c|}{ STATEMENTS } & \multicolumn{1}{|c|}{ VISITORS } & N & Mean & St.D. \\
\hline \multirow{2}{*}{$\begin{array}{l}\text { The event was worth spent } \\
\text { money/time/effort }\end{array}$} & INTERNATIONAL & 436 & 4.38 & .702 \\
\cline { 2 - 5 } & DOMESTIC & 703 & 4.28 & .812 \\
\hline $\begin{array}{l}\text { The event provided greater more value in } \\
\text { comparison to other gastronomic events }\end{array}$ & INTERNATIONAL & 418 & 3.74 & .800 \\
\cline { 2 - 5 } & DOMESTIC & 683 & 3.88 & .945 \\
\hline \multirow{2}{*}{ I will visit this event again } & INTERNATIONAL & 427 & 4.32 & .821 \\
\cline { 2 - 5 } & DOMESTIC & 687 & 4.50 & .750 \\
\hline
\end{tabular}

Source: Data processed by authors

The comparison of agreement with statements relating to value aspects of events between domestic and international visitors shows that there is a difference in the opinions regarding the level of agreement in three event aspects, namely concerning whether it was worth attending events in relation to what was spent, the event value in comparison with similar gastronomic events and inclination to make a repeated visit to the event (table 6). Although the international visitors believe that they have benefited from a better value for what they spent, domestic visitors believe that the event offers greater value in relation to other gastronomic events, expressing thus greater probability of a repeated visit to the same event and perceiving more positively Istria as a gastronomic venue.

\section{CONCLUSION}

By this paper, the intention was to determine whether there is a difference between domestic and foreign visitors to gastronomic events and the main research question reads: Is there a difference in the satisfaction and experiences of event visitors depending on whether they are domestic or foreign?

The research results showed that according to the event visitors' country of origin, the domestic visitors went through a larger share of transforming experiences while participating in gastronomic events in Istria in relation to international visitors. The detailed analysis of the visitor expenditure at gastronomic events showed that the domestic visitors to gastronomic events spend on average $€ 3.00$ less than the international visitors. Domestic visitors are most satisfied with the diversity of the gastronomic offer, while they are least satisfied with the prices. It is completely opposite with foreign guests; they are satisfied with the prices, but less satisfied with what is on offer. Both domestic and foreign visitors are most satisfied with the staff courtesy and their professionalism, while they are least satisfied with the provision of information about event staging. Also, both these groups believe that the gastronomic events which they have attended did not offer greater value in comparison with others, which indicates that, in promotion, there is a need to emphasise the uniqueness of each event respectively.

In the end we can conclude that the behaviour of domestic and international visitors to gastronomic events in Istria is different and that, in programme creation and planning of the event contents, event organisers must consider different mentalities, i.e. depending on whether their target audience is domestic or international. 
ToSEE - Tourism in Southern and Eastern Europe, Vol. 5, pp. 705-714, 2019

K. Trošt Lesić: DIFFERENCE BETWEEN DOMESTIC AND INTERNATIONAL VISITORS TO ...

\section{ACKNOWLEDGEMENTS}

The work on this paper has been financed by Administrative Department for Tourism of the Istrian Region within the project "Analysis of selected gastronomic events and perceptions of Istria as gourmet destination" held in 2016 by the Institute of Agriculture and Tourism in Poreč, Tourism Department. Neither the Administrative Department for Tourism of the Istrian Region nor the Institute of Agriculture and Tourism are responsible for any of the arguments presented in this article.

\section{REFERENCES}

Coppola, M.E. (2016), "Food, tourism, and culture: the keys to success of a global trend", viewed 14 January 2019, https://www.trekksoft.com/en/blog/food-tourism-culture-keys-success-global-trend

Hall, C.M. (2006), “Culinary tourism and regional development: From slow food to slow tourism?”, Tourism Review International, 9, 4, pp. 303-306.

Hall, C.M. \& Mitchell, R. (2006), "Gastronomy, food and wine tourism", In B. Dimitrios, C Carlos (eds), Tourism Business Frontiers: Consumers, Products and Industry, Elsevier, ButterworthHeinemann, pp. 137-148.

Getz, D. (1997), Event Management \& Event Tourism, 1st Edition, Cognizant Communication, New York.

Lee, C., Lee, Y. \& Wicks, B.E. (2004), "Segmentation of festival motivation by nationality and satisfaction", Tourism Management, 25, 1, pp. 61-70.

Oh, H., Fiore, A. \&, Jeoung, M. (2007), "Measuring Experience Economy Concepts: Tourism Applications", Journal of Travel Research, 46, 2, pp. 119-132. https://doi.org/10.1177/0047287507304039

Pine, B.J. and Gilmore, J.H. (1998), "Welcome to the experience economy", Harvard Business Review, JulyAugust, pp. 97-105

Taks, M., Chalip, L., Green, B.C. \& Kesenne, S. (2009), "Factors Affecting Repeat Visitation and Flow-on Tourism as Sources of Event Strategy Sustainability”, Journal of Sport \& Tourism, 14, 2-3, pp. 121 142

Institute of Agriculture and Tourism (2016), Analysis of selected gastronomic events and perceptions of Istria as gourmet destination, Institute of Agriculture and Tourism in Poreč, Tourism Department. Poreč

Woo, E., Yolal, M., Cetinel, F. \& Uysal, M. (2011), "A comparative study of motivation across different festival products", viewed 20 January 2019 , http://scholarworks.umass.edu/cgi/viewcontent.cgi?article=1087\&context=gradconf_hospitality

World Tourism Organization (2012), Global Report on Food Tourism. UNWTO, Madrid.

World Tourism Organization (2017), Affiliate Members Report, Volume sixteen - Second Global Report on Gastronomy Tourism, UNWTO. Madrid.

Yeoman, I., Robertson, M., Ali-Knight, J. Drummond, S. \& McMahon-Beattie, U. (2007), Festival and events management, an international arts and culture perspective, Butterworth-Heinemann, Elsevier, Oxford.

Klara Trošt Lesić, PhD, External Associate

Juraj Dobrila University of Pula

Faculty of Economics and Tourism "Dr. Mijo Mirković"

Zagrebačka 30, 52100 Pula, Croatia

Phone: +385-95-9148008

E-mail: klara@eventor.hr 